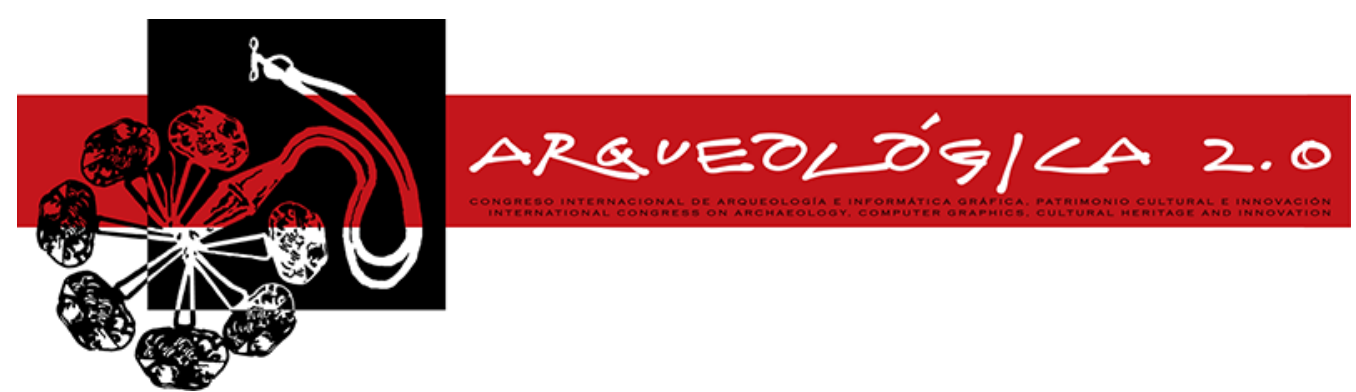

Proceedings of the $8^{\text {th }}$ International Congress

on Archaeology,

Computer Graphics,

Cultural Heritage and Innovation

'ARQUEOLÓGICA 2.0'

in Valencia (Spain),

Sept. $5-7,2016$

DOI: http://dx.doi.org/10.4995/arqueologica8.2016.2976

Received: $11 / 02 / 2016$

Accepted: 01/04/2016

\title{
APLICACIÓN DE TÉCNICAS DE INGENIERÍA INVERSA PARA LA DOCUMENTACIÓN GRÁFICA Y GEOMÉTRICA DEL PATRIMONIO EN UN PROYECTO DE REALIDAD AUMENTADA: UN PRODUCTO MUSEOGRÁFICO PARA LA CATEDRAL DE LA SEO DE ZARAGOZA
}

\author{
APPLICATION OF INVERSE ENGINEERING TECHNIQUES BASED ON GRAPHICAL AND GEOMETRICAL \\ DOCUMENTATION OF HERITAGE TO AN AUGMENTED REALITY PROJECT: A MUSEOLOGICAL PRODUCT FOR \\ LA SEO CATHEDRAL OF ZARAGOZA
}

\author{
Juan Monzón
}

Departamento de Ingeniería de Diseño y Fabricación, Centro Politécnico Superior, Universidad de Zaragoza, María de Luna 3, 50018 Zaragoza, España. jmonzongasca@gmail.com

\begin{abstract}
:
This article addresses a project aimed to the diffusion of the Capilla de San Marcos cultural heritage. The project for this chapel, also called Capilla del Monumento de la Catedral del Salvador de Zaragoza, is based on augmented reality. After studying its history and researching on this cultural object, metric and graphic digitization were carried out by using reverse engineering, laser scanner and photogrammetry techniques. Processing that information thanks to new technologies has allowed generating methodological conclusions that focus on the creation of a museographic product about this singular place that will be helpful to understand the monument's historical and artistical context and, of course, to contribute to the Spanish heritage diffusion.
\end{abstract}

Key words: Heritage, laser scanner, reverse engineering augmented reality, 3D printing, museographic product.

\section{Resumen:}

El presente artículo muestra un proyecto de difusión de patrimonio cultural para la Capilla de San Marcos o también denominada Capilla del Monumento de la Catedral del Salvador de Zaragoza basado en la realidad aumentada. Tras una revisión histórica e investigación del bien cultural, se procedió mediante técnicas de ingeniería inversa, escáner láser y fotogrametría, a su digitalización métrica y gráfica. El procesamiento de esta información gracias a las nuevas tecnologías, ha permitido generar unas conclusiones metodológicas enfocadas a la creación de un producto museográfico de este espacio tan singular que sirva para la comprensión histórico-artística del monumento y por supuesto, para la difusión del patrimonio español.

Palabras clave: Patrimonio, escáner láser, ingeniería inversa, realidad aumentada, impresión 3D, producto museográfico.

\section{Introducción}

La necesidad de documentar el patrimonio históricoartístico ha sido una constante a lo largo del tiempo, con el fin de poder estudiar y conservar los bienes culturales. Las técnicas empleadas han variado a lo largo de las épocas perfeccionándose hasta la actualidad, en que se hace imprescindible el uso de las nuevas tecnologías para documentar y explicar correctamente los bienes culturales.

El presente proyecto consiste en primer lugar, en documentar gráfica y geométricamente la capilla de San Marcos, también denominada Capilla del Monumento, mediante técnicas de ingeniería inversa. En segundo lugar, el proyecto trata de procesar esa información, para generar unas conclusiones metodológicas que conlleven la creación de un producto museográfico para la capilla, que sirva para la comprensión históricoartística del monumento y por supuesto, para la difusión del patrimonio aragonés.

La metodología llevada a cabo consta de tres partes fundamentales. Comenzamos con un estado de la cuestión, revisando las fuentes bibliográficas de lo general a lo particular, desde los monumentos de Semana Santa en Aragón a las descripciones específicas de la capilla del Monumento. En cuanto a las 
fuentes documentales, aunque no son muy numerosas, nos han permitido reconstruir "el escenario del Monumento" o la empaliada de tapices y pasillo solemne que perduró hasta la década de los 70 del siglo XX. En una segunda parte, analizamos detalladamente los aspectos técnicos derivados del uso de la ingeniería inversa, destinados a la documentación de bienes culturales. Para la medición de estos datos, en el trabajo de campo se han utilizado técnicas de digitalización de grandes volúmenes, como láser escáner terrestre y fotogrametría. Por último, tras la toma e interpretación de estos datos, se ha procedido al diseño de un producto museográfico basado en técnicas de realidad aumentada (videomapping), para entender el estado ideal de la capilla y su funcionamiento.

\section{Estado de la cuestión de la Capilla del Monumento o Capilla de San Marcos}

Desde principios del siglo XVI hasta finales del siglo XVIII, la arquitectura efímera desempeñó un papel primordial en los ámbitos sociales, políticos y artísticos hispánicos. Estas construcciones realizadas en materiales maleables y de escasa consistencia (maderas, cañas, estopa, telas, cartón, papeles, cal y escayola), eran levantadas con la intención de crear un vistoso escenario que durase únicamente durante el corto tiempo de las ceremonias para las que habían sido concebidas. Estas arquitecturas efímeras pretendían buscar efecto y causar admiración en aquéllos que las contemplasen. En el caso de la monarquía, eran símbolos de demostración de poder, así como muestra de esplendor victorioso para la Iglesia Católica en festividades señaladas.

En el ámbito religioso estas estructuras (arcos de triunfo, pórticos, pabellones, edículos...) se construían para eventos tales como canonizaciones de santos, consagraciones de templos o capillas singulares, procesiones y otras ceremonias y festividades como el Corpus Christi. Por similitud formal y funcional caben destacar los monumentos de Semana Santa, máquinas a mitad efímeras y temporales, que sólo se montaban en el interior de las iglesias el día del Jueves de Pasión, guardándose sus piezas en un almacén durante todo el resto del año (Bonet 1993).

De cualquier modo, para el tema que nos ocupa, nos centramos en el día de Jueves Santo, que abre el Triduo Pascual, día en que Jesús instituyó la Eucaristía en el marco de la Cena Pascual. Es el sacramento como expresión permanente de Cristo hasta la Parusía.

Como dicen en su trabajo Calvo y Lozano (2004), los denominados "monumentos de Semana Santa" o "monumentos pascuales" son una singularidad dentro de las arquitecturas provisionales, también nombradas en las fuentes como "arte de las tramoyas" (debido a su marcado componente escenográfico) o "arte para el caso" (por su uso coyuntural y esporádico). Parece ser que el origen de estas construcciones se remonta a las ceremonias paralitúrgicas bajomedievales relacionadas con la Pasión de Cristo, para alcanzar su máximo esplendor durante el Barroco, debido al reforzamiento que el misterio eucarístico experimentó a raíz del Concilio de Trento y al consiguiente auge de las festividades del Jueves Santo y del Corpus Christi.
Se considera que los monumentos de Semana Santa comenzaron a plantearse como estructuras arquitectónicas independientes en los albores del siglo XVI (Morte 1986). En Aragón se conservan ejemplos desde el siglo XVII, entre ellos podemos destacar los de Ateca, Bolea, Carenas, Ibdes o el de Fuentes de Ebro. No obstante la escasa calidad de los materiales con los que se realizaban, los daños infligidos durante la instalación y desmantelamiento, así como los gustos artísticos de cada momento que obligaban a reformarlos o sustituirlos, han impedido que lleguen hasta nuestros días. Afortunadamente para nuestro patrimonio histórico-artístico, en el siglo XVII y sobre todo en el XVIII, los monumentos comenzarán a dejarse instalados de forma permanente en espacios concretos (generalmente capillas), que cerradas mediante puertas o telones, preservarán su naturaleza hasta la actualidad (Ibáñez 2006).

En concreto, en el caso de Aragón, uno de los ejemplos más notables de monumentos levantados de forma permanente, es el que se encuentra en una de las capillas de la catedral del Salvador de Zaragoza. Existen varias descripciones acerca de la capilla de San Marcos o también denominada del Monumento (Gascón de Gotor 1939) (Fig. 1). La gran síntesis y descripción que de ella hace Esteban (1977) y en la que nos basaremos en los próximos párrafos, nos permite acercarnos a este espacio singular de forma fidedigna con el objetivo de entender sus aspectos formales y funcionales:

"La capilla de San Marcos, cuyo retablo oculta el Monumento de Semana Santa (Fig. 2), es la primera del lateral del Evangelio del templo de La Seo, entrando por la puerta de la Pabostría, a los pies de la iglesia. Es un recinto cuadrado, cubierto por una cúpula semiesférica montada sobre pechinas y coronada por una linterna [...]. El retablo es un gran lienzo que ocupa toda la pared (Fig. 3): simula con gran habilidad pictórica un retablo de madera de grandes proporciones, de un solo cuerpo con remate; su aparente estructura es convergente, formada por dos pares de columnas, [...]. Las paredes de los laterales las cubren dos grandes lienzos atribuidos a Pablo Raviella hijo, en los que se representa la entrada triunfal de Jesús en Jerusalén, y el beso de Judas". Dichas pinturas barrocas han sido objeto de estudio por parte del profesor Lozano (2010).

Continuando con la descripción de Esteban Lorente: " $L a$ magnífica portada, esculpida en yeso, desarrolla un programa simbólico en torno a la pasión y exaltación de Cristo como víctima propiciatoria [...]. Para el montaje del escenario del monumento de Semana Santa es preciso descender el gran lienzo del retablo que, por medio de unas carruchas, un gran torno y unas sogas, se oculta en una caja del subterráneo del trasaltar de la capilla; así, tras montar una tarima elevada y unas gradas de acceso, se nos patentiza la nueva función del recinto" (Fig. 4).

Este lienzo, actualmente en paradero desconocido, se encontraba sobre un gran soporte de madera compuesto de dos partes: Una es rectangular mientras que la otra tiene la forma semicircular del arco que cierra ocultando la escalinata. Estas dos partes están unidas por una serie de bisagras que permiten plegar la parte superior (semicircular) sobre la inferior para ocultarlo en el foso situado en el sótano, haciéndolo 
descender por un carril de madera situado a ambos lados a modo de guía (Fig. 5). Por debajo del soporte del telón discurren dos sogas que en un extremo estan ancladas a la pared del foso mientras que en el extremo opuesto se enroscan sobre un torno simple oculto en el sótano (Fig. 6). Este mecanismo tensa la cuerda haciendo ascender el telón.

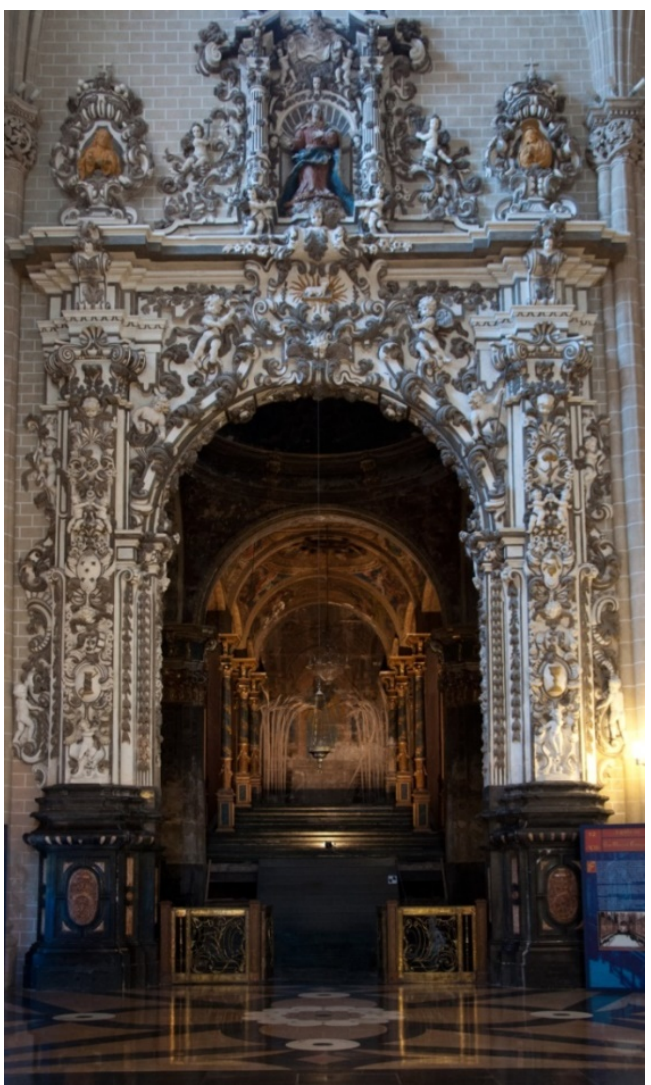

Figura 1: Vista exterior de la capilla de San Marcos (Capilla del Monumento). Catedral del Salvador de Zaragoza.

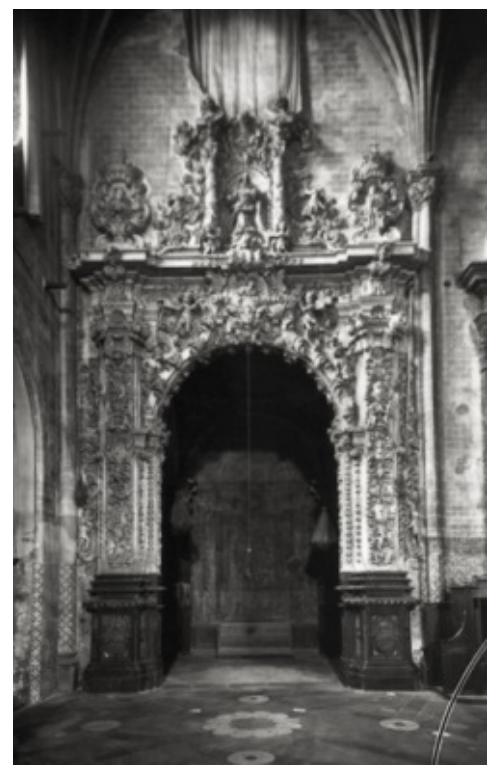

Figura 2: Fotografía antigua de la capilla de San Marcos con el telón cerrado. Fuente: Archivo Histórico Provincial Zaragoza-

Archivo Arte Aragonés. ES/AHPZ-MF/MORA/001734-

"Zaragoza, La Seo. Capilla de San Marcos. Estilo: Barroco." Juan Mora Insa.

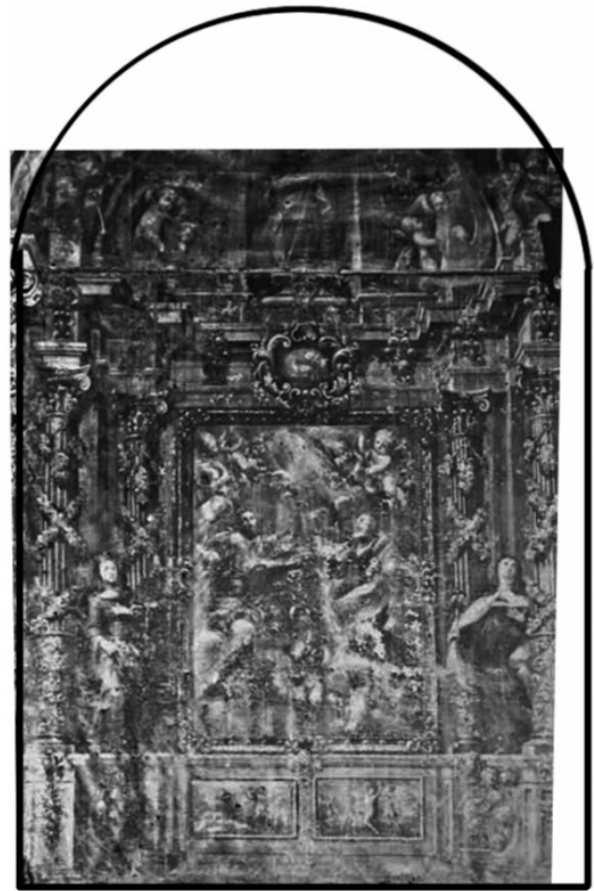

Figura 3: Reconstrucción esquemática sobre fotografía de archivo del telón original de la capilla de San Marcos.

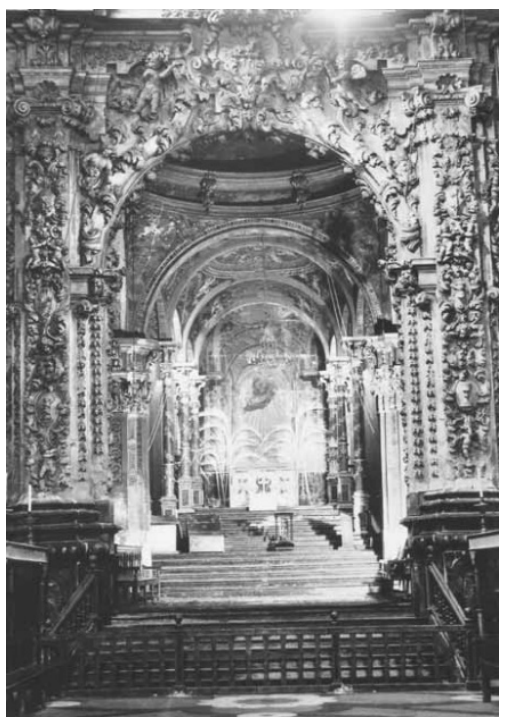

Figura 4: Capilla del Monumento montada. Fuente: Esteban Lorente, Juan Francisco, Op. Cit. 1977 p. 99.

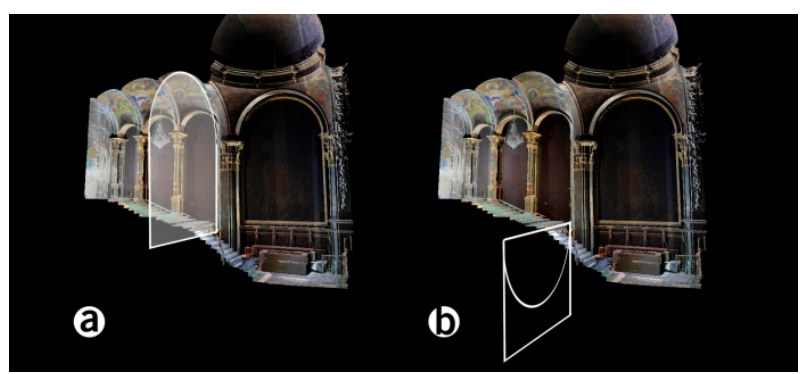

Figura 5: a) Esquema del telón ocultando la escalinata del Monumento de la capilla de San Marcos. b) Esquema del telón recogido dejando a la vista la escalinata del Monumento, en la que se puede apreciar las dos partes que lo forman. 


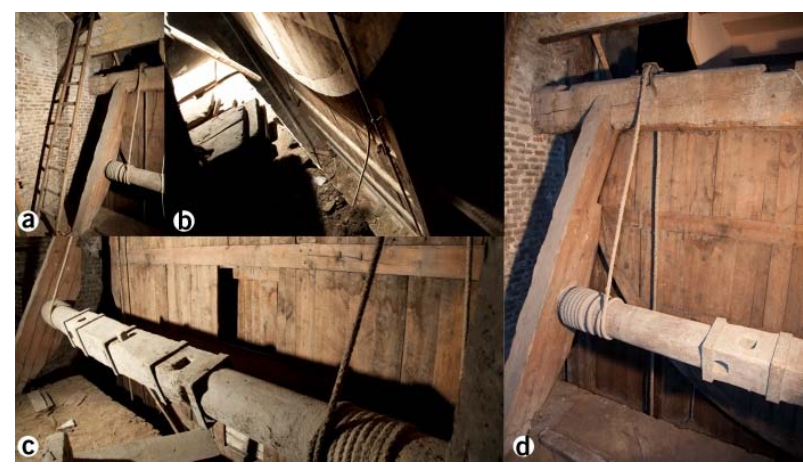

Figura 6: a) Escalera de acceso al sótano de la capilla del Monumento. b) Vista interior del foso en la que se distinguen las dos cuerdas cuerdas y la parte semicircular plegada sobre la rectangular. c) Mecanismo de elevación del telón por medio de un torno simple. d) Torno, soga y polea del mecanismo. Soporte del telón plegado.

Como dice la descripción del profesor J.F. Esteban (1977): "El monumento de Semana Santa es todo él, un auténtico escenario de madera, incluyendo las bóvedas; una verdadera arquitectura provisional que nos ha llegado hasta hoy con la misma función que cuando se concibió. Su estructura general es convergente. Tras una grada de nueve peldaños, se flanquea la rica portada de la capilla que sirve de maravilloso marco al conjunto, penetrando así en el primer espacio, el de la capilla de San Marcos, acondicionada ahora a modo de escenario teatral con una plataforma desnivelada situada algo más alta de la mitad de su zócalo; [...]. Sucede a esta plataforma, en un precipitado ritmo, una gradería de tres tramos flanqueada de columnas ricamente decorada en las bóvedas, todo convergente hacia el altar, y en el muro del fondo aún se ha simulado la continuación de tres tramos más de esta estructura, y un cuarto, que forma cabecera recta, y del que avanza la figura del Padre Eterno; así, ilusionísticamente, a mitad mismo de este largo espacio, se ha colocado un altar de rocalla, que, con espejos, simula plata bruñida y es el que sirve de pedestal a la urna del Monumento" (Fig. 7)

Este frontal de altar (Fig. 8) está realizado íntegramente en madera, cuyas dimensiones son $183 \mathrm{~cm}$ de largo por $103 \mathrm{~cm}$ de alto, sin contar los añadidos de aproximadamente $30 \mathrm{~cm}$ de ancho. La parte delantera está dividida en tres partes de madera cuya ornamentación calada deja a la vista el espejo posterior. En el centro, sobre el espejo (que está roto) hay una cruz y dos palos que partiendo y apoyados en la parte baja, llegan hasta el extremo de los brazos de la misma, donde terminan el de la derecha en una esponja y el de la izquierda en la lanza. En el centro de la cruz y debajo de INRI, aparece la corona de espinas. En la parte derecha del frontal se representan la escalera, el martillo, los clavos y las tenazas. A la izquierda la columna, los azotes, palma y mano de la bofetada. Siendo todos estos elementos de la Pasión de Cristo. Enmarcando éstos y sujetando los espejos, tallado en la madera, hay un conjunto de ornamentación barroca en forma de $S$ en la parte alta y de $C$ en la baja. Las formas de la izquierda son normales, las de la derecha son las letras invertidas. El resto del frontal está lleno de decoración de volutas, ramas, hojas esquematizadas, y espejos, completando todas estas formas en pintura plateada.

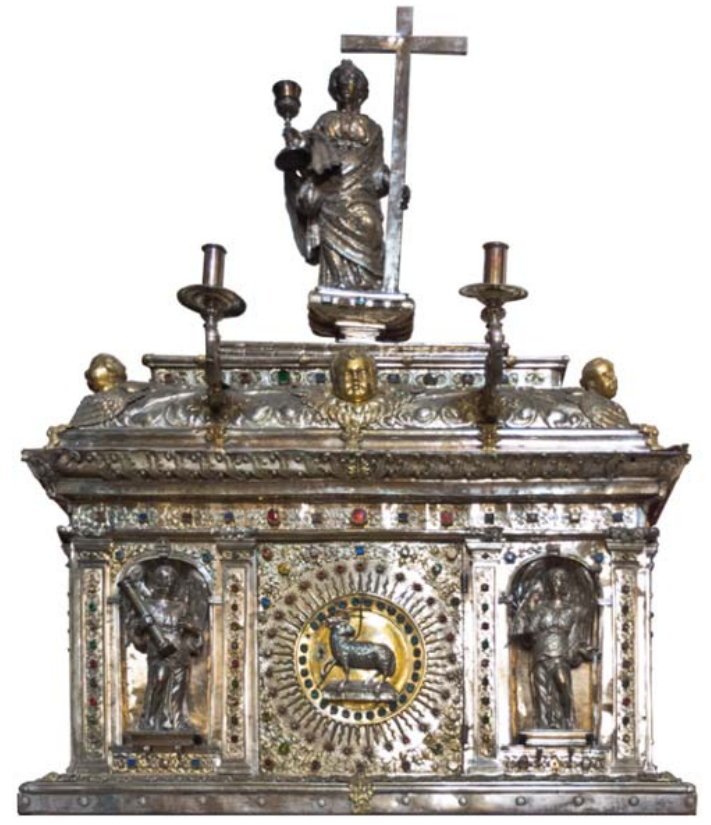

Figura 7: Arca del Monumento. Catedral del Salvador de Zaragoza.

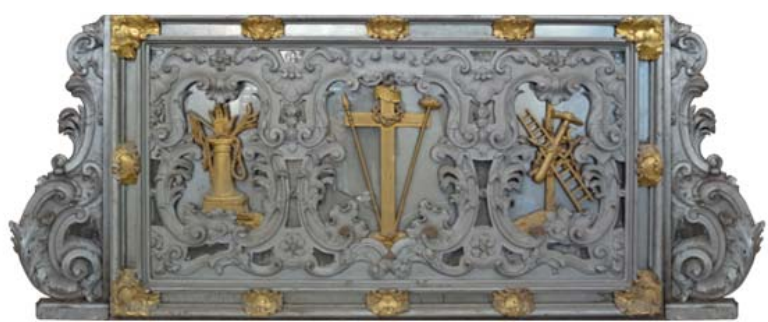

Figura 8: Frontal de altar para la capilla del Monumento. Catedral del Salvador de Zaragoza.

Todo el frontal está enmarcado, como si fuera un cuadro, con listones donde hay colocados, entre espejo y espejo, unos adornos: en la parte inferior y superior tres y en los laterales uno, en las esquinas cuatro florones también pintados en dorado como sucede con los elementos pasionarios.

Finalizamos la descripción del frontal de altar de nuevo con las palabras del profesor Esteban Lorente: "[...] La decoración pictórica de las bóvedas es de gran logro ilusionista, y se ve apoyada por la creciente luz hacia el fondo. No hay que olvidar el inestimable recurso que supone delimitar la nave situada en su frente por medio de ricos tapices -creando un impresionante recinto abocinado-, [...]".

En cuanto a las fuentes documentales, el Inventario del Archivo Capitular de la Catedral del Salvador (1906), detalla cuáles eran los tapices de la colección que se utilizaban:12 tapices de raz grandes que representan los doce meses del año; 8 paños de raz que representan la Historia de Moisés; 10 paños de raz grandes: 6 azules y 4 colorados, con vestuarios muy antiguos; 2 paños de raz con la historia de San Juan; 2 paños de raz en forma de reposteros y 5 paños de raz de distintas historias.

Según los diferentes documentos y fotografías que han aparecido en la investigación realizada en este trabajo, la empaliada estaba compuesta en primer lugar por una estructura a modo de pasillo, formada por una serie de 
columnas y travesaños de madera ornamentada que delimitaban el recorrido desde la fachada de la epístola, a la altura de la capilla Santa Elena, hasta la capilla del Monumento. Estas columnas se encajaban en un orificio sobre un pie de madera apoyado en el suelo. En su parte superior acaban en forma de $T$ dónde descansan los travesaños que las unen, y sobre los cuales se insertan hachones para cirios a lo largo de todo el recorrido. En segundo lugar los tapices eran sujetados a un largero de madera por su parte posterior y suspendidos del techo de la catedral mediante cuerdas por un sistema de poleas, colocándolos por encima de la estructura de madera anteriormente explicada, dejando libre la parte inferior para el tránsito de los fieles. Un ejemplo similar de este sistema lo encontramos en las explicaciones que da De la SalaValdés (1933) sobre el Monumento de Semana Santa de la Iglesia de San Pablo de Zaragoza y las fotografías de Juan Mora Ínsa (1905-1954) y de Manuel Coyne (1954) del Archivo Histórico Provincial de Zaragoza.

La disposición de los tapices de La Seo de Zaragoza debió de cambiar a lo largo de su existencia puesto que los documentos que constan del pasado siglo nos ofrecen diferentes puntos de vista de su montaje. En la lámina 51 del libro "Zaragoza Monumental" (Magaña 1919) que data de 1919 se observa como la empaliada constaba de dos alturas de tapices a ambos lados del pasillo (Fig. 9), mientras que en la fotografía de 1962 del Boletín Municipal (Beltrán 1962), en la que se aprecia el Monumento ya montado en Semana Santa con la candelería encendida, figura solamente una única altura de tapices (Fig. 10). El acceso a este recinto se realizaba al final del lado de la Epístola a la altura de la capilla de Santa Elena, donde la fila de tapices quedaba interrumpida. En la fotografía de 1976 del profesor Esteban Lorente aparecen dos tapices reposteros con el escudo del Duque de Calabria en el lado opuesto a la portada del Monumento. El resto de tapices que se colocaban se conocen por el inventario de 1906, pero no se dispone de ningún documento que nos aclare el orden de su colocación.

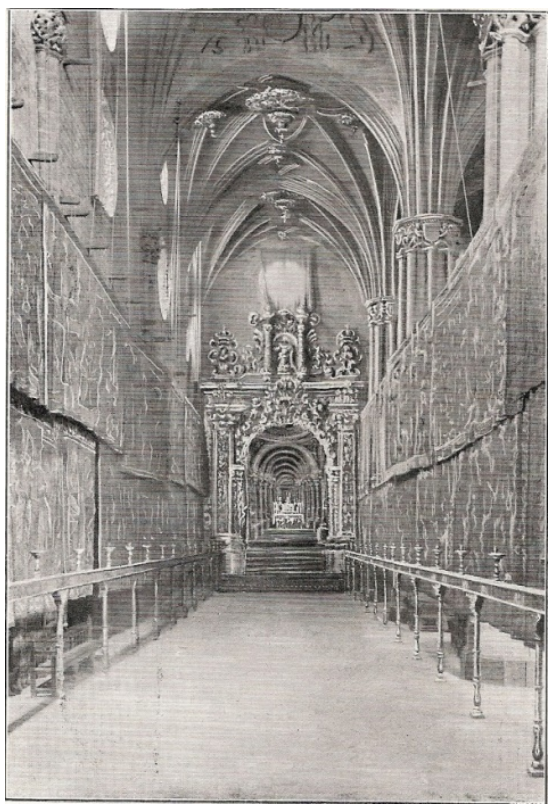

Figura 9: Empaliada con dos filas de tapices (1919). Fuente: "Zaragoza Monumental", lámina 51.

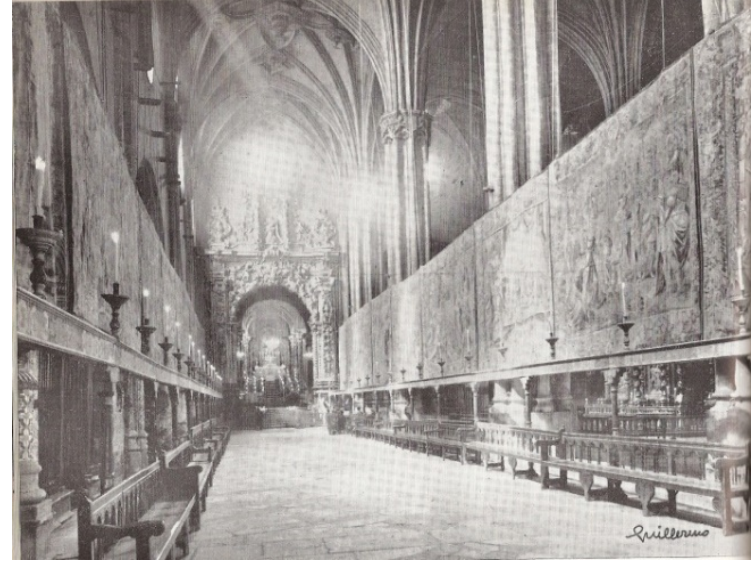

Figura 10: Empaliada con una fila de tapices (1962). Fuente: Boletín Municipal de Zaragoza, p.24.

A partir de esta interesante noticia documental, podemos reconstruir visualmente la empaliada que cumplía la función de pasillo solemne para la procesión al Monumento y que perduró hasta que se declaró la Catedral de La Seo en estado de ruina a finales del siglo XX, (Fig. 11 y 12).

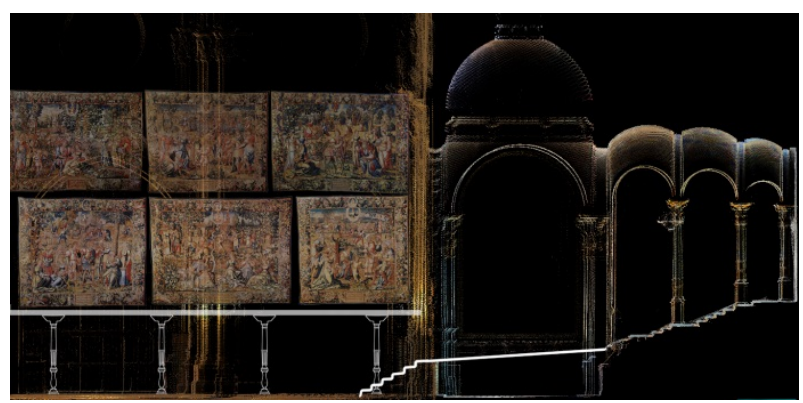

Figura 11: Reconstrucción digital de la empaliada original sobre nube de puntos de la sección transversal de la capilla de

San Marcos. Basado en fotografía de la empaliada de 1919.

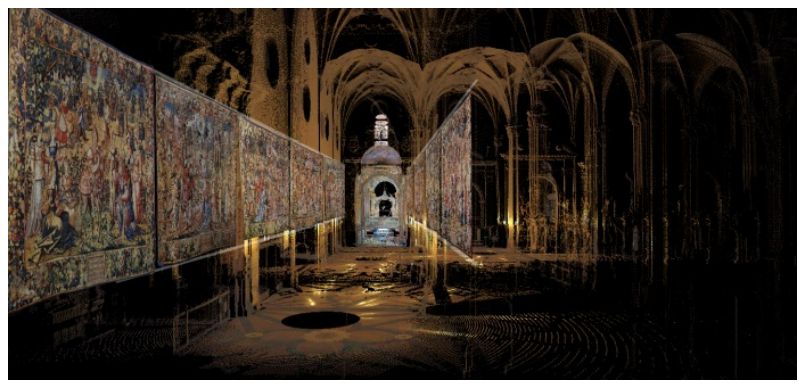

Figura 12: Reconstrucción digital de la empaliada original sobre nube de puntos de la vista frontal de la capilla de San

Marcos. Basado en fotografía de la empaliada de 1962.

El último elemento que nos queda por describir de la Capilla del Monumento, es su portada de ingreso. Está realizada en yeso y descansa sobre dos pedestales tallados en piedra negra de Calatorao en la que figuran esculpidas en jaspe rojo las armas heráldico-religiosas del Arzobispo Crespo-Agüero; letra "Y" surmontada de corona real cerrada y flanqueada por una estrella de seis puntas a cada lado. Sin lugar a duda, la descripción que mejor documenta el resto del arco de ingreso es la de la Dra. Boloqui Larraya (Fatás 2008): "La portada de ingreso [...], es obra del escultor José Serra en el año 1711. Su estructura arquitectónica, de carácter 
churrigueresco, parece derivar de la de Santo Dominguito de Val, situada en el lado de la Epístola. Novedad interesantísima respecto a su modelo es la sustitución de las pilastras del ático por columnas de fuste estriado enguirnaldadas, las primeras documentadas en Zaragoza. Todo el frontis, incluido el intradós del arco, va decorado con profusa talla de hojas carnosas, cabezas de angelitos y tarjetones con los símbolos de la Pasión. En medio de la gran cartela del arco aparece el Cordero místico sobre el libro de los siete sellos, flanqueado por ángeles portadores de Las Armas de Cristo o instrumentos de su Pasión. Sobre el entablamento, en la hornacina central, se localiza la alegoría de la Iglesia, arrodillada y suplicante, a la que escoltan cabezas de serafines, con nuevos símbolos de la Pasión (Fig. 13). A los lados, hay dispuestos sendos tarjetones conteniendo respectivamente, un jarrón, símbolo de la Redención por el Bautismo, y una linterna que significa el poder de la Gracia. En los extremos, dentro de cartelas recortadas, están los bustos de María y Juan Evangelista; como coronamiento, la imagen del Padre Eterno entre algodonosas nubes".

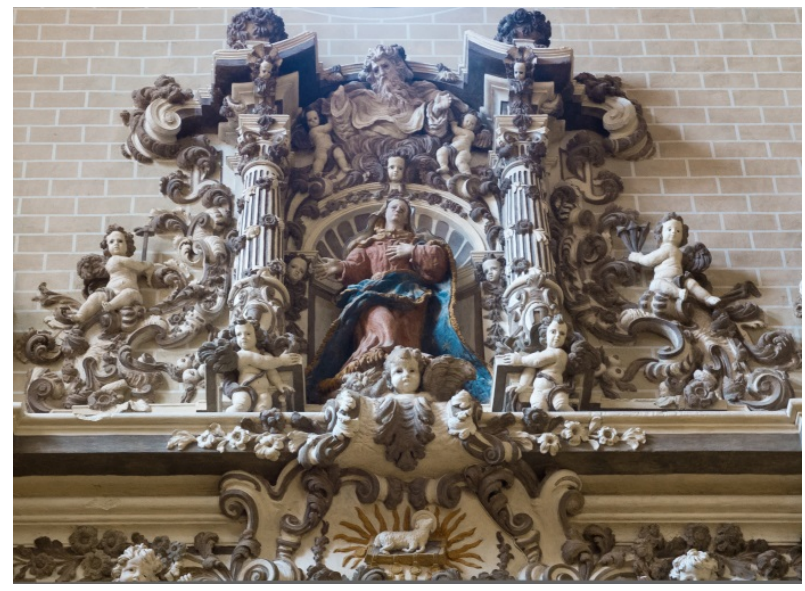

Figura 13: Detalle de la portada de ingreso. Hornacina central con la alegoría de la Iglesia y representación del Padre Eterno.

De este sucinto estado de la cuestión, se desprende la importancia que tiene la documentación del patrimonio a la hora de estudiar y conservar los bienes culturales. En la actualidad gracias a las nuevas tecnologías, partiendo del rigor documental y bibliográfico, contamos con recursos que nos permiten abordar este tema con nuevas y refrescantes perspectivas.

\section{Aspectos técnicos del proyecto: utilización de la ingeniería inversa para la documentación de la Capilla de San Marcos}

El término "documentación" puede definirse como el procesamiento y registro de información que proporciona un compendio de datos con un fin determinado. Cada trabajo de documentación es distinto y los resultados que se obtienen son únicos para cada caso. Esto implica que los métodos y equipos empleados a la hora de documentar el patrimonio, se adecúen a las finalidades deseadas y a las precisiones prefijadas.

Al hablar de documentación del patrimonio, basándonos en la clasificación del profesor Lodeiro (1995), podemos diferenciar dos grupos de documentos ("métricos" o "no métricos"), que implican distintas labores de actuación.

La documentación no métrica, generalmente está destinada a labores divulgativas y didácticas, en su gran mayoría museos en los que se incluyen modelos en tres dimensiones o representaciones virtuales $360^{\circ}$ de un objeto. Los métodos más comunes basados en esta técnica son las descripciones y el uso de fotografías e imágenes, fotos panorámicas o modelos virtuales, que sirven para trazar un plan de actuación en una posible restauración, o imágenes radiográficas y reflectográficas que permiten desvelar información subyacente de una obra pictórica, utilizando una cámara sensible en la zona del infrarrojo.

Hasta la fecha, la documentación que consta de la capilla de San Marcos, es exclusivamente de carácter "no métrico": descripciones por parte de diversos autores, fotografías, gráficos esquemáticos y documentos escritos de archivos particulares, así como fuentes directas o testimonios verbales. Además de las fotografías ya comentadas en este artículo, podemos citar una serie de plantas, alzados y secciones de 1919 del Arquitecto Julio Bravo (1919); un recibo de 1920 del taller de pintura Hijos de Silvestre Gracia (1920) para reparar la capilla y los esquemas gráficos y fotografías del profesor Esteban (1970). A partir de estos datos resultaría muy complicado dejar correctamente documentada la capilla desde el punto de vista gráfico y geométrico. Ni siquiera las fotografías que constan, nos darían la información suficiente para recuperar pinturas o elementos arquitectónicos en el caso de que éstos se perdieran; de ahí la importancia de utilizar formas de documentación más precisas y completas.

Por otro lado, la documentación métrica permite un registro exacto del bien, lo que implica definir su geometría en un momento determinado, obteniendo alzados, secciones, perfiles y mapas de daños. Además, si se realiza en distintos momentos, se puede obtener un estudio temporal que permitiría elaborar un seguimiento de los movimientos, deformaciones o volumen de la materia perdida. Las medidas con cinta, topografía y rectificación son métodos muy comunes, mientras que el escáner láser y la fotogrametría, son técnicas menos empleadas debido a su reciente aplicación.

El escáner láser es una técnica de ingeniería inversa, que permite obtener un modelo tridimensional en el que se cuenta con una documentación tanto geométrica como gráfica del patrimonio. (Angás 2010) Gracias a esta tecnología, somos capaces de registrar datos que por otros métodos serían imposibles de definir. La gran desventaja es el tratamiento de la nube de puntos obtenida, ya que el software de procesado es complejo y caro. Con esta técnica no se toca el bien cultural, por lo que no se introducen deterioros adicionales. Es por ello que se ha escogido esta técnica no destructiva para trabajar en la capilla de San Marcos, ya que es la más conveniente para desarrollar el producto museográfico. La toma de datos se llevó a cabo en dos sesiones diferentes: por un lado se procedió a escanear el interior de la capilla, mientras que por otro, se escanearon la portada y las naves de la catedral.

En cuanto a la capilla de San Marcos se dispusieron en la parte baja de la misma y en las escaleras ascendentes, tres luminarias (luz fluorescente) de modo 
que quedasen iluminados los dos lienzos laterales y el interior del recinto. Más tarde, se procedió a colocar un conjunto de siete dianas circulares, con un patrón en blanco y negro, que sirvieron para unir un total de tres escaneados permitiendo documentar la capilla geométricamente en su totalidad (Fig. 14). Una vez dispuestos estos adhesivos, se continuó con el montaje del escáner láser de diferencia de fase Leica HDS 6100 (LINK http://hds.leicageosystems.com/downloads123/hds/hds/HDS6000/broc hures-datasheet/HDS6100 Datasheet us.pdf ) sobre un trípode que descansa en una estrella de apoyo. Después de su calibrado, procedimos al escaneo por control remoto desde un ordenador portátil, realizando en primer lugar un barrido láser que registró todos los puntos de la capilla a una resolución preestablecida obteniendo una nube de puntos. Posteriormente se realizaron escaneados parciales a mayor resolución de los puntos diana. Estos puntos o localizaciones comunes, permitieron la unión de diferentes escaneados con mayor facilidad. Mediante este proceso la geometría de la capilla queda registrada, tras lo cual, sin mover el trípode, se procedió a fotografiar la capilla, sustituyendo el escáner láser por una cámara fotográfica, de modo que la lente quedase ajustada con su mismo eje. Las fotos tomadas (ocho fotografías por cada escaneado), deberán ajustarse a la nube de puntos para generar tres imágenes equirrectangulares que documentan la capilla gráficamente por completo (Fig. 15).

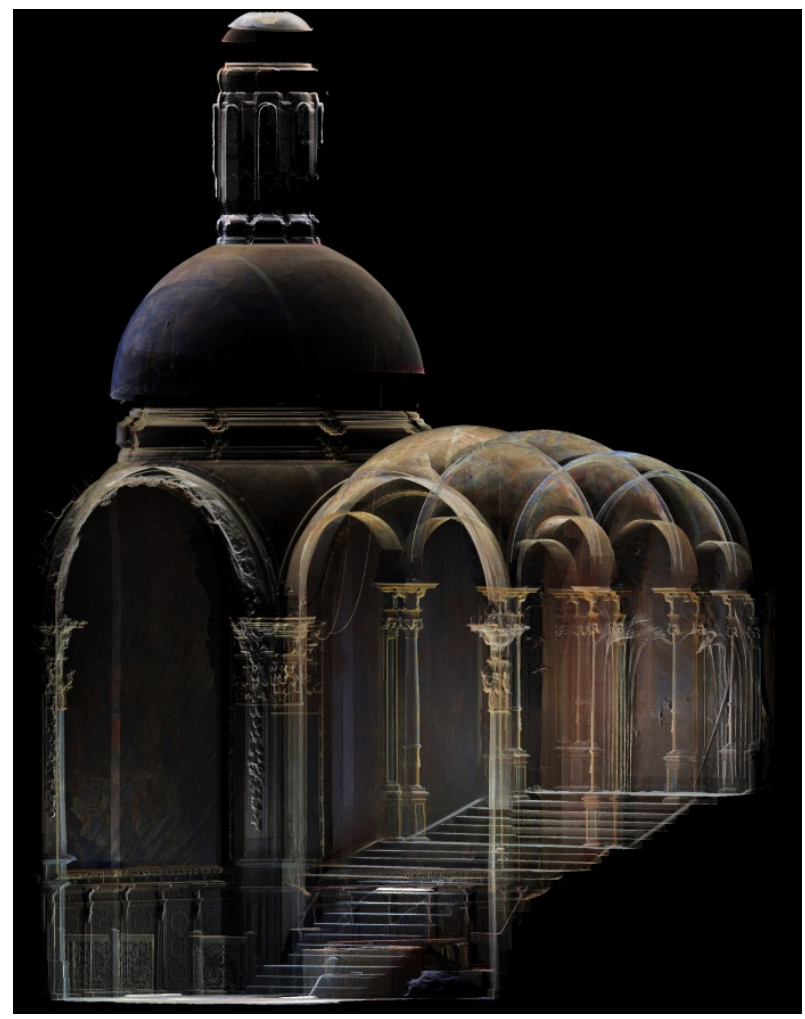

Figura 14: Nube de puntos que documenta geométricamente la capilla.

Para digitalizar la portada de la capilla y las naves de la catedral, la forma de proceder fue muy similar a la que se cita en el párrafo previo. Aunque en este caso, a fin de comparar métodos de trabajo y resultados con respecto al escáner anterior, se optó por utilizar un escáner de tiempo de vuelo Leica C10 (Fig. 16) (LINK http://hds.leica-

geosystems.com/downloads $123 /$ hds/hds/ScanStation $\% 2$ 0C10/brochures-

datasheet/Leica ScanStation C10 DS en.pdf ) que registró datos geométricos y gráficos en el mismo proceso. Este escáner consta de una memoria interna y es independiente de un ordenador externo que lo controle. Una vez que fueron configurados los parámetros deseados, el escáner tardó 40 minutos en completar cada uno de los tres barridos que fueron necesarios para registrar el exterior de la capilla (Fig. 17).

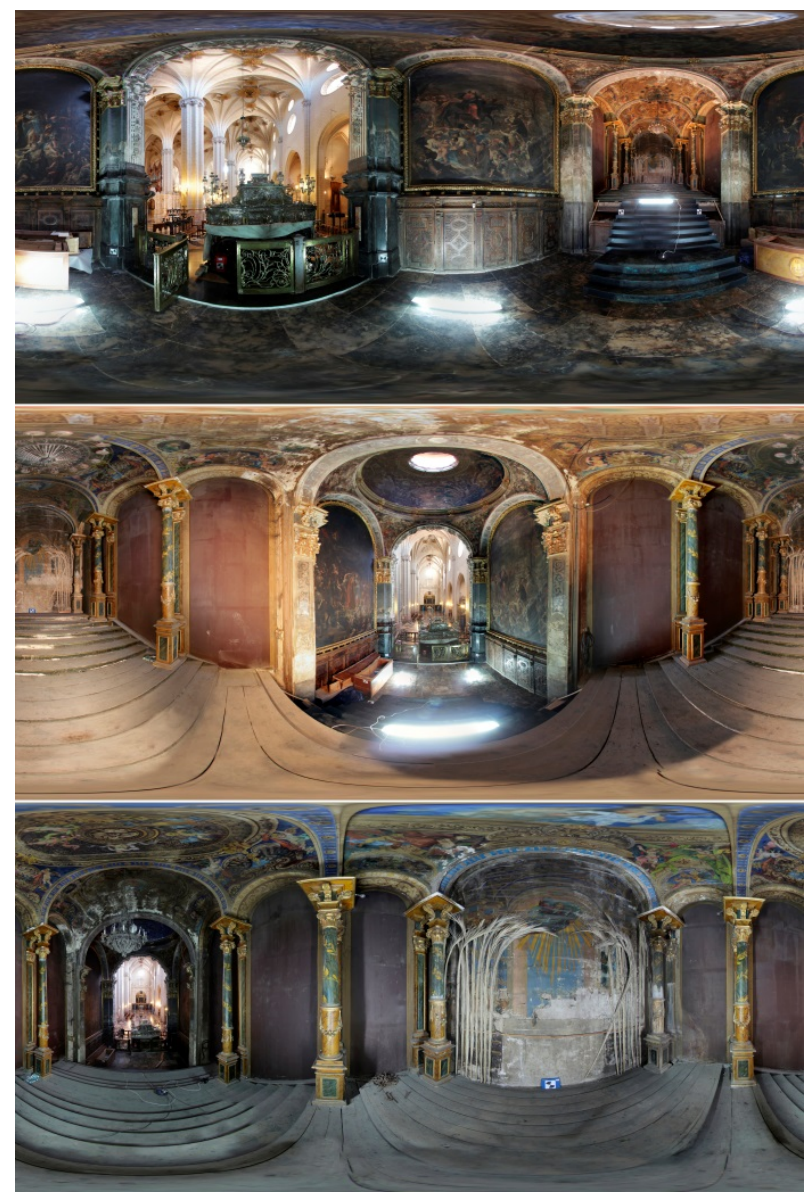

Figura 15: Conjunto de imágenes equirrectangulares que documentan gráficamente la capilla.

Tras la toma de datos y escaneos necesarios para registrar en su totalidad todos los puntos que se necesitaban, se procedió al tratamiento de los mismos mediante el programa Leica Cyclone (LINK http://survey.crkennedy.com.au/sites/default/files/downlo ads/Leica\%20Cyclone\%20Basic\%20User\%20Manual\%2 0-\%20January\%202015.pdf ), para seleccionar aquéllos destinados al diseño del producto museográfico. Para el manejo de la nube de puntos de la portada de la capilla de San Marcos, fue necesario utilizar una serie de software específicos para cada una de las tareas, con el objetivo de imprimir la portada en tres dimensiones, mediante técnicas de prototipado rápido para su posterior uso en una maqueta a escala. 


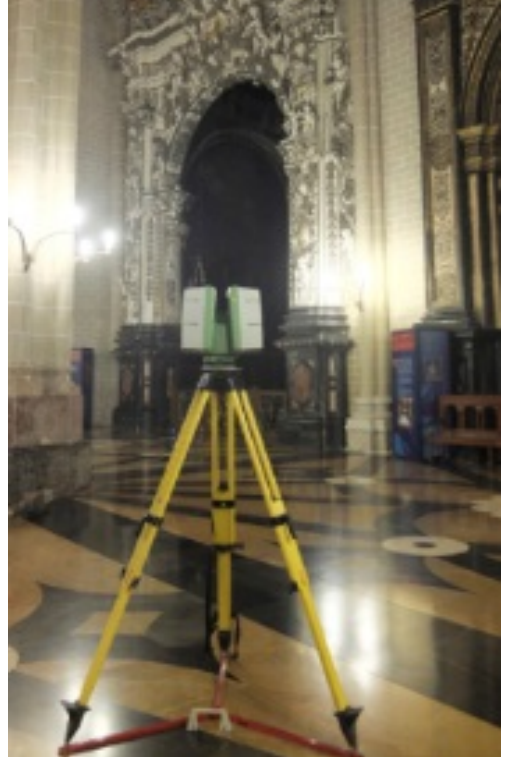

Figura 16: Escáner Leica $\mathrm{C} 10$ en las naves de la catedral del Salvador de Zaragoza.

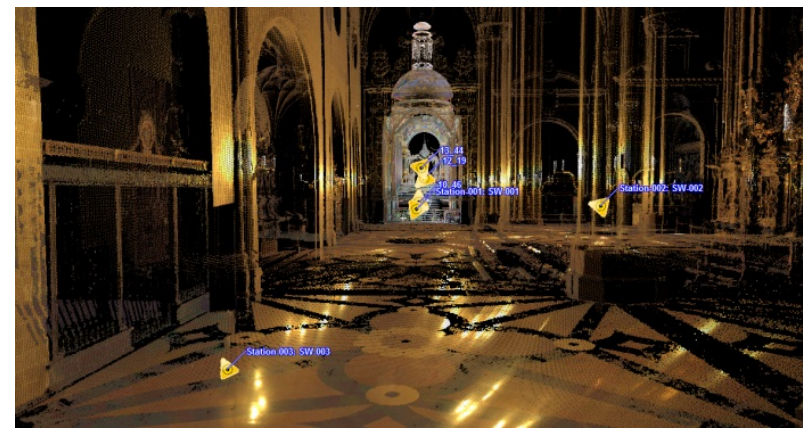

Figura 17: Estaciones de escaneo para el registro de datos exterior a la capilla.

El tratamiento general consistió, mediante el software Geomagic Studio12 (LINK http://www.dirdim.com/pdfs/DDI Geomagic Studio Wra p 2012.pdf ), en triangular las nubes registradas con el fin de obtener una superficie (malla de polígonos altamente refinados), ya que al tratarse de una portada libre y de gran complejidad, no se necesitaba grado de parametrización, por lo que no era necesario realizar un modelo CAD (Fig. 18).

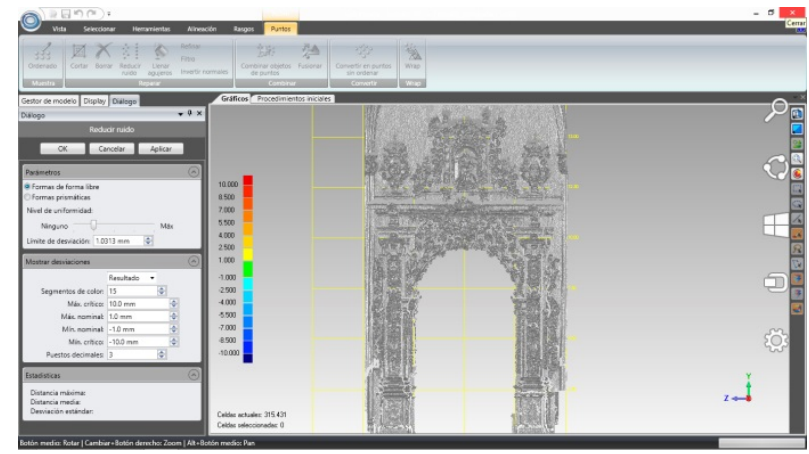

Figura 18: Captura de pantalla del programa Geomagic Studio $12^{\text {TM }}$

Debido a la gran cantidad de detalles de la portada, fue necesario exportar la malla de polígonos altamente refinados a un software de modelado $3 D$ denominado Zbrush $4 R 6 \quad$ (LINK http://pixologic.com/zbrush/downloadcenter/documentati on/ ). Gracias a este software, se pulieron las superficies de forma más sutil que con Geomagic Studio12. Además, se reconstruyeron parte de los ángeles y detalles de la portada reajustando la geometría para hacerla lo más fiel a la realidad, disminuyendo el ruido y consiguiendo una imagen más nítida (Fig. 19).

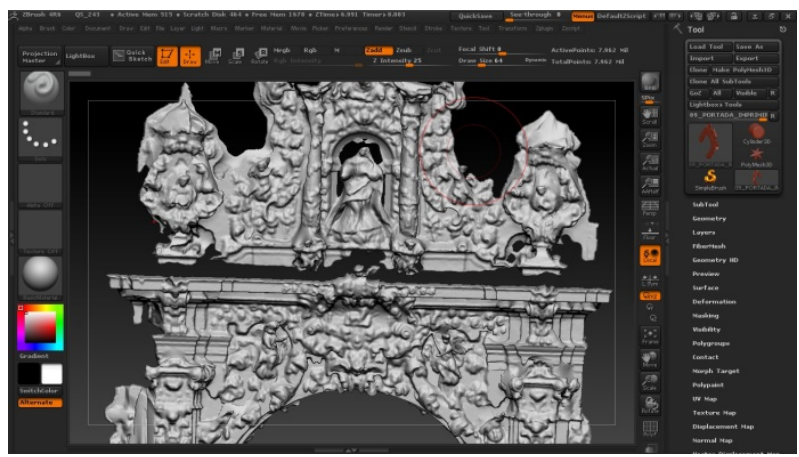

Figura 19: Captura de pantalla del programa Zbrush $4 R 6$.

Como se puede apreciar, la ingeniería inversa permite la digitalización y el posterior tratamiento de objetos físicos mediante programas (Geomagic, Polyworks, Zbrush, ...). En nuestro caso se trabajó con la nube de puntos y se realizó un modelado escultórico de ajuste preparándolo en formato .OBJ para la impresión me diante técnicas de prototipado rápido.

Se entiende como prototipado rápido el proceso de fabricar artículos mediante la adición de capas ya sean de metal, plástico, cerámica u otros materiales. La impresión 3D puede ser utilizada en distintos ámbitos, desde la medicina, el prototipado, la aeronáutica, hasta aplicaciones en el ámbito doméstico. En este caso la tecnología de adición de capas ha sido utilizada con fines museográficos, imprimiendo la portada de ingreso para realizar una maqueta a escala 1:50 de la capilla (Fig. 20).

Para la impresión fue necesario convertir el archivo .OBJ al estándar .STL (Standard Triangulation Languange). Este formato es una discretización de la pieza mediante triángulos, los cuales vienen referenciados por las coordenadas de sus ejes y un vector normal en la superficie. De esta manera el programa reconoce las caras interiores y exteriores. Cuantos más puntos posea el STL más triángulos habrá y más fiel será el archivo. Para continuar con la impresión, se necesita preparar el archivo STL importándolo a un programa de slicing que divida al modelo $3 \mathrm{D}$ en capas y genere las trayectorias que más tarde interpretará la impresora.

El software de la impresora Object EDEN $350 \mathrm{~V}$ (Stratasys Inc.) (LINK http://www.3dvision.com/pdf/3Dprinting/design-series/Objet-Eden350 350V.pdf

utilizada en este proyecto permite gestionar diferentes puntos clave en la impresión, como son la orientación y distribución de la pieza, las estructuras de soporte, la generación de capas y la trayectoria del cabezal para imprimir la portada. Esta acción, es un proceso automático desatendido que tiene una duración variable en función del tamaño del objeto a imprimir. Consiste en la adición de capas (entre 16 y $30 \mu \mathrm{m}$ ) de un polímero 
acrílico líquido, polimerizado por radiación ultravioleta tras ser depositado por el cabezal. Tras la fabricación de la portada de ingreso, se realizó el postproceso de la pieza, eliminando el material de soporte y realizando tratamientos para mejorar la calidad superficial así como sus propiedades físicas.

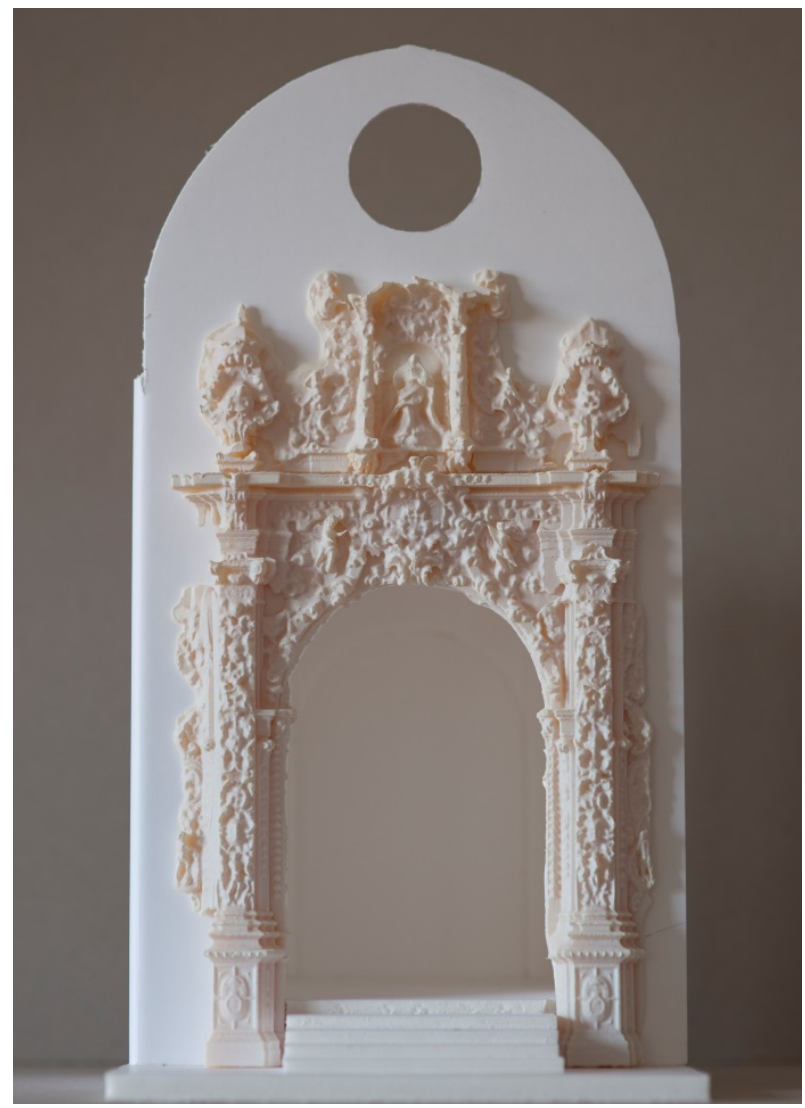

Figura 20: Maqueta a escala de la capilla de San Marcos con la portada impresa mediante técnicas de prototipado rápido $(30 \mathrm{~cm} \times 20 \mathrm{~cm})$.

\section{Propuesta museográfica para la capilla del Monumento: El uso de técnicas de realidad aumentada}

Después de haber analizado los aspectos técnicos, queda patente la utilidad de la ingeniería inversa en la documentación de bienes culturales y la importancia que tiene a la hora de ser empleada en productos museográficos que permitan la difusión del patrimonio (Ruiz 2010).

Hasta hace un tiempo, la museografía se había sostenido en métodos tradicionales en los que no había interacción entre el usuario y el bien cultural. Pero desde hace unos años, se está comenzando a tener en cuenta este aspecto, llegando a soluciones como la utilización de recursos tecnológicos acordes a nuestro tiempo, que mejoran la experiencia del usuario con técnicas como por ejemplo la realidad aumentada.

El videomapping es una técnica audiovisual de realidad aumentada que consiste en la proyección de luz sobre un objeto tridimensional del espacio real que permite proyectar imágenes, texturas o vídeos, con el objetivo de crear en el espectador un estímulo sensorial en la percepción.
Uno de los ejemplos museográficos más destacados a nivel nacional donde se ha empleado esta técnica es el de la iglesia románica de San Clemente de Tahull (LINK https://vimeo.com/87102885 ). Esta iglesia que fue construida entre los siglos XI-XII y fue declarada Patrimonio Mundial por la Unesco en el año 2000. Consta de una proyección audiovisual animada que mediante 6 proyectores de alta definición reproduce virtual y fielmente las pinturas originales del ábside mayor (Fig. 21). Las pinturas del ábside que había hasta ahora (que eran una reproducción de las originales hecha en 1960 por Ramon Millet) se conservan ahora en un museo anexo en la misma zona. Los frescos originales se conservan en el Museo Nacional de Arte de Cataluña en Barcelona.

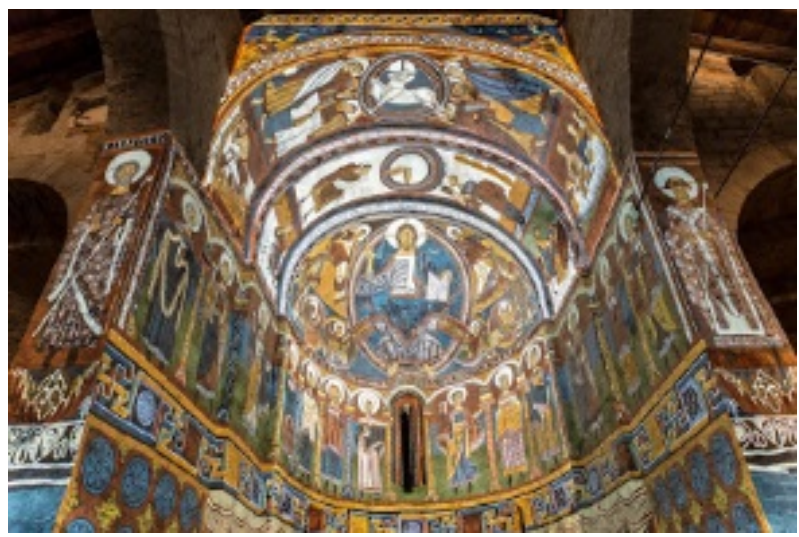

Figura 21: Reconstrucción mediante videoproyección de los frescos románicos de San Clemente de Tahull. Lérida

A continuación abordaremos los elementos fundamentales que constituyen la técnica del videomapping con la intención de diseñar un producto museográfico para la capilla de San Marcos. El sistema de proyección, la superficie proyectada, los puntos de visualización y los contenidos, son los aspectos a tener en cuenta.

Un sistema de proyección consta de diferentes características que afectan de forma directa en la proyección final. El sistema óptico influye en el proceso de calibración del mapeado, ya que determina el frustum o cono de proyección del proyector. Este sistema está formado por: el ratio que indica la relación entre la distancia del foco y el ancho del área de proyección; el shift que representa el desplazamiento del eje óptico y el focal, la longitud del sistema óptico. El resto de elementos que forman el sistema de proyección son la relación de aspecto, luminosidad, definición, contraste y parámetros intrínsecos y extrínsecos del proyector.

Las superficies donde se puede videoproyectar son continuas o discontinuas. Las continuas son aquellas superficies lisas o curvas como cúpulas, columnas o esferas, mientras que las discontinuas tienen geometrías más complejas, ya que constan de diferentes planos de proyección. Ambas son independientes del material sobre el que se proyecte.

Un proyecto de videomapping puede llevarse a cabo de diferentes formas. El objetivo final siempre trata de adaptar una proyección a una superficie del espacio real para ser vista desde un punto de visualización concreto. Cada técnica tiene sus ventajas y sus inconvenientes, que generalmente tienen que ver con la 
espectacularidad de la proyección y la complejidad del montaje. Para realizar el set up es necesario comprender el montaje desde tres elementos diferentes: objeto, proyector y espectador. El punto de visualización donde se coloca el espectador influye de forma decisiva en la percepción de la videoproyección, cuestión que se ha tenido en cuenta a la hora generar los contenidos para el producto museográfico para la capilla de San Marcos. En la mayoría de los casos este problema se soluciona ubicando a los espectadores y el sistema óptico en el mismo lugar. Es por este motivo que cuando la perspectiva del contenido no coincide con la del espectador, el efecto 3D no es coherente.

Existen varias formas a la hora de videoproyectar y ajustar la proyección al espacio real. La primera de ellas es el pintado directo, útil para casos simples. Éste no requiere de calibración ni necesita un programa de edición de imagen. Es imprescindible no mover ni el proyector ni el objeto sobre el cual proyectamos, ya que el efecto 3D solo se aprecia desde un único punto de vista. Por el contrario, MeshWarping (QuadWarpingHomografía) se utilizan para geometrías más complejas, ya que precisan de un mallado previo de la proyección, que posteriormente se ajusta a la superficie del espacio real. El resto de formas precisan de un modelado $3 D$ de la escena, ya que son sistemas complejos basados en visión por computador que utilizan una imagen real y un mapa de profundidad para modelos de interactividad.

La generación de contenidos es el último elemento que constituye la técnica de videomapping. Como ya hemos dicho, una de las principales características de esta tecnología es la adaptación de los contenidos a la superficie de proyección, para lo cual es necesario realizar un estudio previo del espacio sobre el cual se quiere proyectar. Una vez estudiada la superficie se puede proceder de dos formas: bien proyectar a partir de un modelado 3D como se ha hecho para el caso de la capilla de San Marcos, o bien proyectar a partir de una plantilla 0 foto generada a través de un procedimiento fotográfico, en el que es necesario contar con una óptica similar a la de proyección.

Antes de abordar el desarrollo del producto museográfico sobre la capilla de San Marcos se realizaron diferentes pruebas en la catedral. Una de ellas se llevó a cabo en el trascoro, tomando una imagen que posteriormente fue procesada coloreando sus distintas partes. Después se proyectó la imagen mallándola y ajustándola a la superficie original (Fig. 22).

De la singularidad de esta capilla surge la necesidad de diseñar un producto museográfico específico para la difusión del patrimonio histórico-artístico de Aragón, basado en técnicas de realidad aumentada; en este caso videomapping. Gracias a esta técnica se puede realizar una fiel reconstrucción del estado original y funcionamiento de la capilla, además de utilizar elementos ficticios estimulando la imaginación del espectador. En caso de llevar a cabo este proyecto se podría diseñar un producto museográfico para ser utilizado en futuras exposiciones en la catedral del Salvador, con una función didáctica, arqueológica y restaurativa, que sirva de referente y motivo para atraer visitantes.

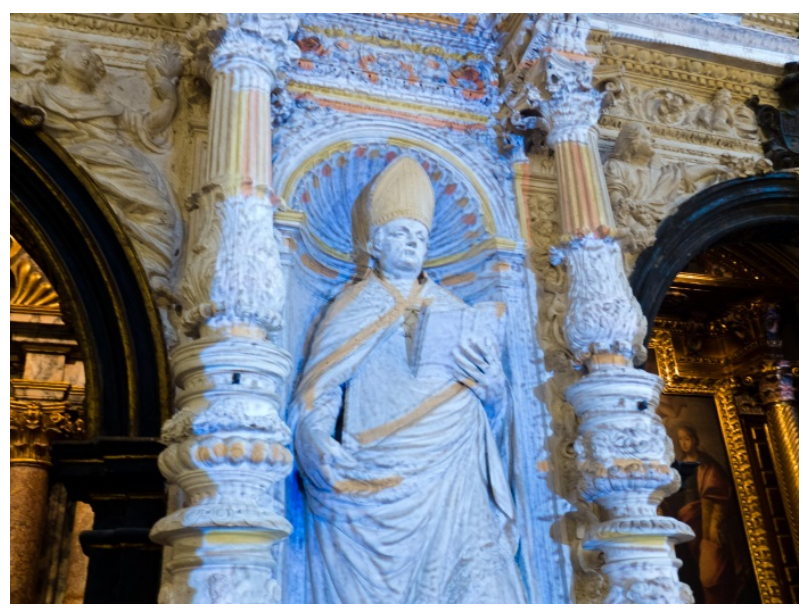

Figura 22: Ejemplo de proyección en realidad aumentada sobre el trascoro de la catedral del Salvador de Zaragoza.

Desde el punto de vista museográfico se procede a estudiar el espacio dando lugar a tres posibles soluciones acordes a los recursos de que se dispone, teniendo en cuenta la aplicabilidad, el coste y la funcionalidad. En la primera opción se decide proyectar sobre toda la superficie que forma la capilla, independientemente de la dificultad de la geometría: en la albanega de la fachada exterior utilizando el ojo de buey que hay en lo alto, así como en el interior de capilla, tanto en la escalinata sobre todas las columnas, como en el lienzo del fondo. En una segunda opción, se puede optar por proyectar únicamente sobre la portada de ingreso, jugando con todos los elementos decorativos que la forman. En último lugar, sería posible proyectar tanto sobre la portada de ingreso como sobre una lona, justo en el sitio donde originalmente estaba situado el telón con el altar fingido (Fig. 23). Además, como función extra, se podría disponer de dos pantallas laterales que cerraran y enmarcaran el espacio de la portada, permitiendo que se puedan proyectar imágenes de los tapices de la colección del Cabildo para simular la empaliada (Fig. 24). a)
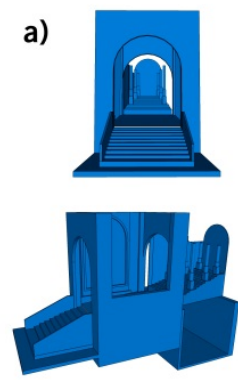

b)
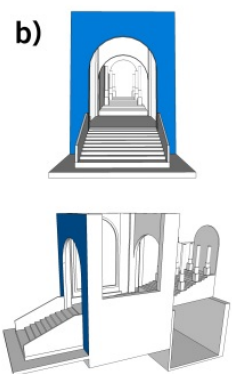

c)
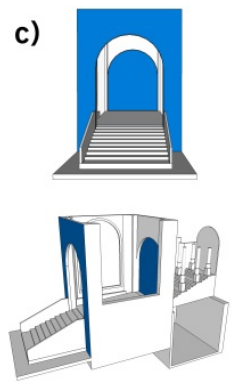

Figura 23: a) esquema del diseño de la proyección sobre todo el espacio, b) únicamente sobre la portada, c) sobre la portada y lona situada en el espacio del telón.

Después de las alternativas anteriormente citadas y tras la evaluación de las mismas, se decide elegir la tercera opción. Esta solución funciona muy bien a nivel compositivo, permitiendo jugar con dos planos a diferentes profundidades de modo que el espectadorusuario pueda entender el espacio en el que se encuentra. De esta forma, al proyectar sobre la lona situada en el interior de la capilla se puede simular el 
uso del antiguo telón, mientras que al hacerlo sobre la fachada de ingreso podemos generar contenidos de mayor libertad visual, minimizando los recursos y aumentando la espectacularidad.

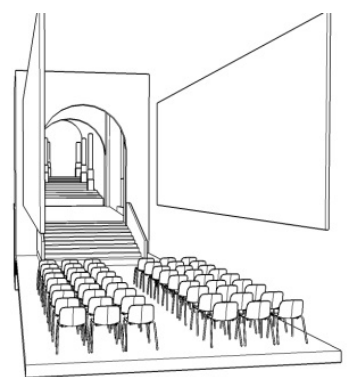

Figure 24: Esquema de dos pantallas opcionales para recrear la empaliada de tapices.

Los contenidos son el conjunto de imágenes, texturas y videos que podrían proyectarse a la hora de diseñar el producto museográfico, permitiendo la recreación del estado original de la capilla, su evolución histórica, su restauración, el proceso de construcción de las perspectivas fingidas, así como el montaje del Monumento de Semana Santa para la ceremonia del Jueves Santo y los elementos que lo componían en el pasado.

Para poner en práctica esta técnica de realidad aumentada se procedió a proyectar diferentes contenidos sobre una maqueta a escala de la capilla, ya que resulta práctico y económico, quedando patente el papel relevante de las nuevas tecnologías en lo que a la documentación y difusión del patrimonio se refiere (Fig. 25).

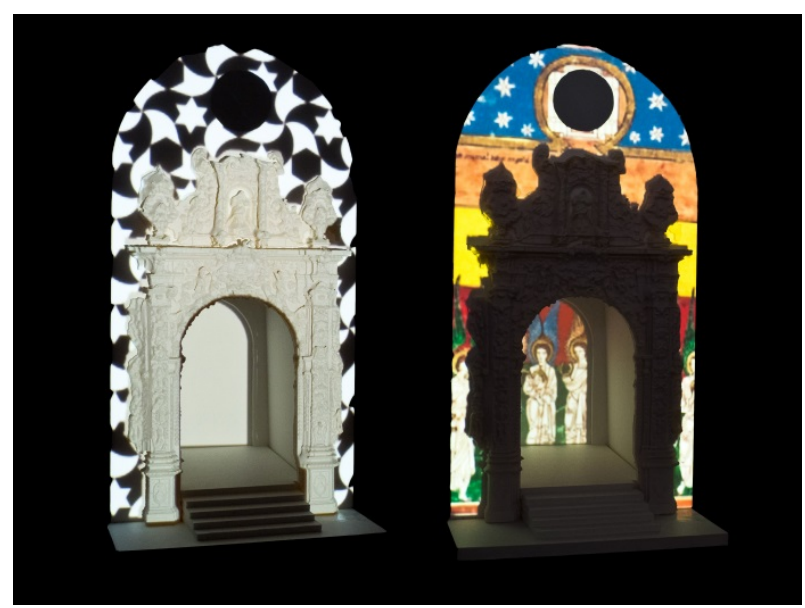

Figura 25: Ejemplos de proyección en la maqueta sobre el alzado de la capilla y el telón

\section{Conclusiones del proyecto}

La elaboración de un producto museográfico para un espacio singular, como es el de la capilla de San Marcos o del Monumento de la catedral del Salvador de Zaragoza, requiere ante todo de un exhaustivo estudio previo documental para el posterior diseño de un producto que permita su difusión. Con el fin de poder estudiar y conservar los bienes culturales, las técnicas de documentación han ido perfeccionándose hasta la actualidad, donde las nuevas tecnologías, en su gran mayoría de carácter métrico como es el caso de la ingeniería inversa, han resultado fundamentales.

Desde hace unos años, se ha comenzado a cuestionar la museografía tradicional, llegando a soluciones en las que se usan recursos tecnológicos acordes a nuestro tiempo. Estas soluciones mejoran la experiencia del usuario, con técnicas como por ejemplo la realidad aumentada y que permiten la interacción con el bien cultural hasta ahora impensable. Es así como se ha dotado de ficción e irrealidad a un espacio que de por sí ya resulta curioso para darle mayor reconocimiento, e ir un poco más allá generando valor añadido mediante la unión de arte e ingeniería.

Hemos visto como el prototipado nos permite restituir piezas del patrimonio. Las técnicas de impresión 3D ayudan a elaborar representaciones a escala con gran precisión, para trazar líneas de actuación y comprobar resultados. El resultado final es un producto museográfico (Fig. 26) basado en técnicas de realidad aumentada, en las que mediante el videomapping se ha conseguido recrear el estado original de la capilla, su evolución histórica, su restauración, el proceso de construcción de las perspectivas fingidas, así como el montaje del Monumento de Semana Santa para la ceremonia del Jueves Santo y los elementos que lo compusieron en el pasado.

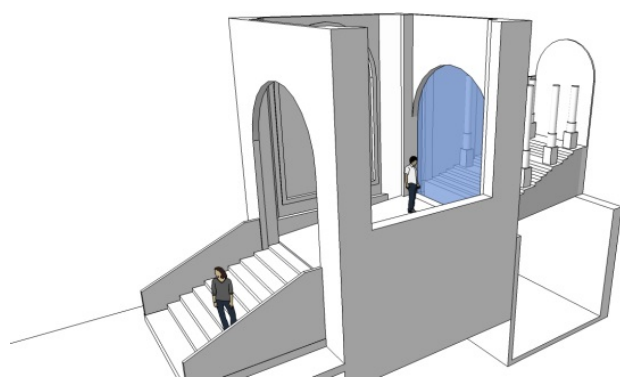

Figura 26: Producto final. Esquema de interacción usuarioproducto. En color azul se muestra la lona retroproyectada.

\section{Referencias}

ANGÁS, J., 2010. Valorización, difusión y estandarización de la documentación geométrica del patrimonio. In Secretaría general técnica de Publicaciones, Información y Documentación. Documentación gráfica del Patrimonio ( $1^{\text {a }}$ Ed. pp.154-163.). Madrid: MEC. Gob España.

BELTRÁN, A., 1962. Los museos de Zaragoza. Zaragoza: Boletín Municipal de Zaragoza, Año 3, №8, página 24, a pie de foto: "Tapicerías colgadas en Semana Santa".

BONET, A., 1993. La arquitectura efímera del Barroco en España. Revista de Arte, n¹3, pp.23-70.

BRAVO, J., 1919. Planos arquitectónicos, №15, documentos 1 y 2 . Archivo Capitular de La Seo de Zaragoza. 
CALVO, J. I. y LOZANO, J.C., 2004. Los monumentos de Semana Santa en Aragón (Siglos XVII-XVIII). Artigrama, núm. 19, pp. 95-137.

DE LA SALA-VALDÉS, M., 1933. Estudios históricos y artísticos de Zaragoza. Zaragoza: Imprenta del Hospicio Provincial. 293 pages.

ESTEBAN, J.F., 1977. La capilla de San Marcos y el Monumento de Semana Santa de La Seo de Zaragoza. Seminario Arte Aragonés, XXII-XXIII-XXIV, pp. 175-180.

ESTUDIO COYNE, 1954. Tapiz de "La Predicación de San Pablo". Archivo Histórico Provincial Zaragoza- Catedral de San Salvador, ES/AHPZ-MF/COYNE/000722-000729. Retrieved May 28, 2016, from http://dara.aragon.es/opac/app/item/arfo?vm=nv\&q=tapiz+manuel+coyne+1954\&p=4\&i=368473

FATÁS, G., 2008. Guía histórico artística de Zaragoza. Zaragoza: Institución Fernando el Católico.

GASCÓN DE GOTOR, A., 1939. La Seo de Zaragoza. Estudio histórico-arqueológico, col. "Arte Aragonés". Barcelona: Ed. Luis Miracle.

IBÁÑEZ, J., 2006. Los decorados de Semana Santa en Aragón en la Edad Moderna en Monuments et décors de la Semaine Sainte en Méditerranée: art, rituels, liturgies, Actes des premières rencontres méditerranéennes sur les décors de la Semaine Sainte. Art et rituels autour des Monuments, Université de Toulouse-Le Mirail. Perpignan, 2325 nov. pp. 45-132.

LODEIRO, J.M., 1995. Aplicaciones de la topografía en la documentación arquitectónica y monumental. Madrid: colegio oficial de ingenieros técnicos en topografía.

LOZANO, J.C., 2010. La pintura barroca en La Seo de Zaragoza: viejos problemas, nuevas visiones, in M. C. Lacarra Ducay. El barroco en las catedrales españolas. Zaragoza: Institución Fernando el Católico.

MAGAÑA, A., 1919. Zaragoza Monumental. Vol 1. Edificios Religiosos. Zaragoza: Artes Gráficas Gregorio Casañal, página 18, Lámina 51, a pie de foto: "Perspectiva del monumento de Jueves Santo".

MORA, J., 1905-1954. Zaragoza, S. Pablo. Tapiz. Estilo: Renacimiento. Rafael Sancio de Urbino. Archivo Histórico Provincial Zaragoza- Archivo Arte Aragonés. ES/AHPZ-MF/MORA/001837-001843. Retrieved May 28, 2016, from http://dara.aragon.es/opac/app/item/arfo?vm=nv\&q=tapiz+renacimiento+rafael+urbino\&p=0\&i=199926

MORTE, M.C., 1986. Monumentos de Semana Santa en Aragón en el siglo XVI. Artigrama: Revista del Departamento de Historia del Arte de la Universidad de Zaragoza, 3, pp 195-214.

RUIZ, J., 2010. ImaginArte. Aplicación de tecnologías 3D en museos y espacios singulares. In Secretaría general técnica de Publicaciones, Información y Documentación. Documentación gráfica del Patrimonio, 1ª Ed. pp.144-153. Madrid: MEC. Gob España.

SILVESTRE, H., 1920. Culto y fábrica. Recibos año 1920. Pinturas Capilla Monumento. Archivo Capitular de La Seo de Zaragoza. 